\title{
DNA microsatellite instability and mismatch repair protein loss in adenomas presenting in hereditary non-polyposis colorectal cancer
}

H Iino, L Simms, J Young, J Arnold, I M Winship, S I Webb, K L Furlong, B Leggett, J R Jass

\begin{abstract}
Background and aim-Hereditary nonpolyposis colorectal cancer (HNPCC), as its name implies, is associated with few adenomas, and the early evolution of colorectal neoplasia is poorly understood. In this study our aim was to clarify the genetic profiles of benign polyps in subjects with HNPCC using a combined molecular and immunohistochemical approach.
\end{abstract}

Methods-Thirty adenomas and 17 hyperplastic polyps were obtained from 24 affected HNPCC subjects. DNA was extracted from paraffin embedded tissue by microdissection and analysed for the presence of microsatellite instability (MSI) and mutations in five genes known to be targets in mismatch repair deficiency (TGFßRII, IGF2R, BAX, hMSH3, and hMSH6). Serial sections were stained by immunohistochemistry for hMLH1 and $\mathrm{hMSH} 2$.

Results-Twenty four (80\%) of 30 adenomas showed MSI. Of MSI positive adenomas, $\mathbf{6 6 . 7 \%}$ showed MSI at more than $40 \%$ of markers (high level of MSI (MSI-H)). Two of 17 hyperplastic polyps revealed MSI at one marker (low level of MSI (MSI-L)). A significant association was found between MSI-H and high grade dysplasia in adenomas $(p=0.004)$. Eight of nine adenomas with mutations of coding sequences revealed high grade dysplasia and all nine were MSI-H. Four of the nine ranged in size from 2 to $5 \mathrm{~mm}$. The presence of the hMSH6 mutation was significantly correlated with high levels of MSI $(80 \%$ of markers) $(p<0.02)$. Twenty four adenomas gave evaluable results with immunohistochemistry. One of six (17\%) microsatellite stable, six of seven $(86 \%)$ MSI-L, and 11 of 11 (100\%) MSI-H adenomas showed loss of either hMLH1 or hMSH2.

Conclusions-Most adenomas in subjects with a definite diagnosis of HNPCC show MSI $(80 \%)$. The finding of MSI-L is usually associated with loss of expression of hMLH1 or hMSH2, unlike the situation in MSI-L sporadic colorectal cancer. The transition from MSI-L to MSI-H correlated with the finding of high grade dysplasia and mutation of coding sequences and may be driven by mutation of secondary mutators such as hMSH3 and hMSH6. Advanced genetic changes may be present in adenomas of minute size.

(Gut 2000;47:37-42)

Keywords: adenoma; microsatellite instability; mismatch repair; hereditary non-polyposis colorectal cancer

The early evolution of colorectal neoplasia in hereditary non-polyposis colorectal cancer (HNPCC) is poorly understood. While it is sometimes possible to demonstrate residual adenomas adjacent to HNPCC cancers, ${ }^{1}$ the use of somatic microsatellite mutations as molecular clocks discloses surprisingly long periods of parallel evolution of adenomas and carcinomas. ${ }^{2}$ This suggests that adenomas and carcinomas may not be so much sequentially related but derived from a common precursor lesion of microscopic dimensions. ${ }^{2}$ This could explain in part the well authenticated observation of interval cancer in HNPCC in which a patient presents with a cancer soon after a negative colonoscopic examination. ${ }^{3}$ Nevertheless, while adenomas are uncommon in HNPCC subjects, a disproportionate number are diagnosed before the age of 50 years, ${ }^{4}$ and they are more likely to be large, have a villous morphology, and show high grade dysplasia. ${ }^{4}$ These observations have introduced the concept of "aggressive adenoma" in HNPCC $^{5}$ in which rapid evolution is driven by the acquisition of genetic instability due in turn to breakdown of the DNA mismatch repair mechanism. ${ }^{6}$

DNA mismatch repair deficiency leads to a high level of microsatellite instability (MSI-H) in cancer tissue. It is generally agreed that $\mathrm{p} 53$ mutation and $17 \mathrm{p}$ and $18 \mathrm{q}$ loss of heterozygosity are infrequent in MSI-H cancers, whether HNPCC $^{7}$ or sporadic. ${ }^{8}$ Genes with repetitive tracts in their coding sequences appear to provide an alternative molecular pathway in the evolution of MSI-H colorectal cancers. These include TGF $\beta$ RII, ${ }^{10}$ IGF2R, ${ }^{11}$ BAX, ${ }^{12}$ $\mathrm{CDX}-2,{ }^{13} \mathrm{E} 2 \mathrm{~F}-4,{ }^{14}$ and caspase $5 .{ }^{15}$ However, while microsatellite instability (MSI) may be established at an early stage in adenoma formation, including microscopic aberrant crypt foci, ${ }^{2} 16$ mutated genes have not been

Abbreviations used in this paper: HNPCC, hereditary non-polyposis colorectal cancer; MSI, microsatellite instability; MSS, microsatellite stable; PCR, polymerase chain reaction; TBS, Tris buffered saline. 


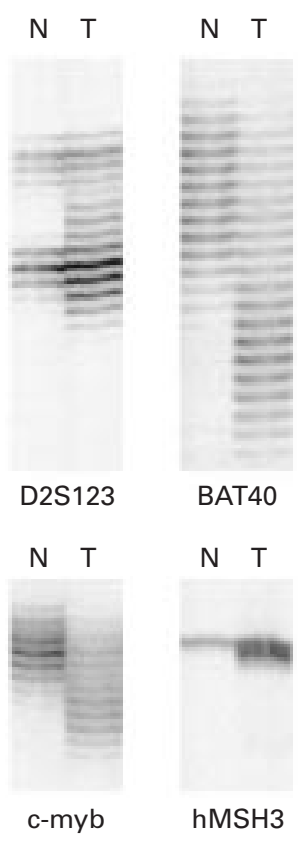

Figure 1 Sample of four loci showing bandshifts, including three

microsatellite loci (D2S123, BAT40, and c-myb) and the poly $(A) 8$ tract of $h M S H 3$. DNA was extracted from a $2 \mathrm{~mm}$ tubular adenoma from a patient carrying a germline mutation of hMSH2.

Despite the small size of the adenoma, all nine microsatellite loci showed instability, as did hMSH6 (not shown). N, normal; $T$, tumour DNA. detected at high frequency in adenomas showing MSI. ${ }^{16} 18$ Mutation of TGF $\beta$ RII has been described as a very early and possibly initiating event $^{16}$ whereas others link the TGF $\beta$ RII mutation to the stage of adenoma-carcinoma transition. ${ }^{18}$ BAX mutations have also been related to adenoma-carcinoma transition. ${ }^{19}$ The extent of genetic instability appears to correlate with the risk of adenoma progression. ${ }^{20}$ It has been suggested that the full development of the microsatellite mutator phenotype depends on the recruitment of "secondary" mutators. ${ }^{21}$ Among these are hMSH3 and hMSH6, mismatch repair genes that are susceptible to the development of frameshift somatic mutations by virtue of their repetitive encoding sequences. ${ }^{21}$

The aim of this study was to stratify a series of adenomas obtained from subjects with a definite diagnosis of HNPCC according to microsatellite status (microsatellite stable (MSS), MSI-low (MSI-L) and MSI-H) and to assess critically the timing of loss of expression of hMLH1 and hMSH2 and recruitment of secondary mutators (MSH3 and MSH6). By correlating these observations with demonstration of mutations in TGF $\beta$ RII, IGF2R, and $\mathrm{BAX}$ as well as the classical morphological risk factors for adenoma progression, it should be possible to derive a clearer picture of the molecular steps governing the origin of cancer in HNPCC.

\section{Materials and methods}

PATIENTS AND POLYPS

Seventeen hyperplastic polyps and 30 adenomas were obtained from 24 affected HNPCC subjects as paraffin embedded archival samples. All families met stringent criteria for HNPCC as defined by the International Collaborative Group for HNPCC. ${ }^{22}$ Additionally, at least two cancers per family were required to show high levels of DNA MSI. Affected subjects were recruited either on the basis of developing an MSI-H colorectal cancer or a HNPCC associated cancer at less than 50 years of age. Twenty two $(73.3 \%)$ adenomas were derived from 10 subjects (members of four different families) carrying a germline mutation in hMSH2 or hMLH1. Of the 24 subjects, 10 were male and 14 were female. Some polyps were obtained by surgical resection of synchronous colon cancers and others by endoscopic polypectomy. Between one and 12 polyps were obtained per subject. Serial sections were cut from each paraffin block and the first of these was stained with haematoxylin and eosin for histopathological diagnosis and to serve as a template for microdissection. All patients gave informed consent to the study which was approved by the local institutional review boards. As there is little accumulated experience on immunohistochemistry for hMLH1 and hMSH2, 83 sporadic $^{8}$ and 46 familial colorectal cancers from the Queensland Bowel Cancer Family Registry known to be either MSS, MSI-L, or MSI-H (unpublished data) were included in the study.
Table 1 Pathological features of hereditary non-polyposis colorectal cancer polyps

\begin{tabular}{lcc}
\hline & $\begin{array}{c}\text { Hyperplastic polyps } \\
(n=17)\end{array}$ & $\begin{array}{l}\text { Adenomas } \\
(n=30)\end{array}$ \\
\hline Location & 2 & \\
$\quad$ Proximal colon & 13 & 8 \\
$\quad$ Distal colon & 2 & 22 \\
$\quad$ Unknown & & 0 \\
Size $(\mathrm{mm})$ & 13 & \\
$<5$ & 4 & 14 \\
$5-9$ & 0 & 9 \\
$10+$ & & 7 \\
Dysplasia & - & 13 \\
$\quad$ Low grade & - & 17 \\
$\quad$ High grade & & \\
\hline
\end{tabular}

DNA PREPARATION AND ANALYSIS OF MICROSATELLITE INSTABILITY

DNA was extracted from microdissected sections of paraffin embedded archival sample as described previously. ${ }^{23}$ DNA from each pair of samples, normal mucosa and tumour, was analysed for MSI at nine loci: MYCL, ${ }^{24} \mathrm{D} 2 \mathrm{~S} 123,{ }^{25}$ D5S346, ${ }^{26}$ D10S197, ${ }^{27}$ D18S58, ${ }^{28}$ BAT25, ${ }^{29}$ BAT 26, ${ }^{29}$ BAT 40, ${ }^{29}$ and c-mybT22. ${ }^{30}$ The loci D10S197 and D18S58 were analysed only in the case of polyps classified as MSS, MSI-L, or borderline MSI-H with seven loci. The reaction volume for the polymerase chain reaction (PCR) was $10 \mu \mathrm{l}$ which included $2 \mu \mathrm{l}$ of the DNA sample, $10 \mathrm{nM}$ of each primer, $2 \mathrm{nM}$ of each deoxynucleotide triphoshate, $1 \mu \mathrm{l}$ of PCR buffer, 2.5 U of Taq polymerase (Boehringer Mannheim, Mannheim, Germany), and $1 \mu \mathrm{l}$ of $\left[{ }^{33} \mathrm{P}\right] \mathrm{dATP}$. PCR was run as previously described. ${ }^{23}$ After amplification, PCR products were separated by electrophoresis in 5\% denaturing polyacrylamide (19:1) gel and visualised by autoradiography. Tumours showing bandshifts at one or more microsatellite markers were termed MSI (fig 1). MSI status was subclassified as high (MSI-H) when bandshifts were seen at three markers (including at least one mononucleotide marker) and low (MSI-L) when less instability was detected. Scoring of MSI was undertaken independently by two observers (HI, JY).

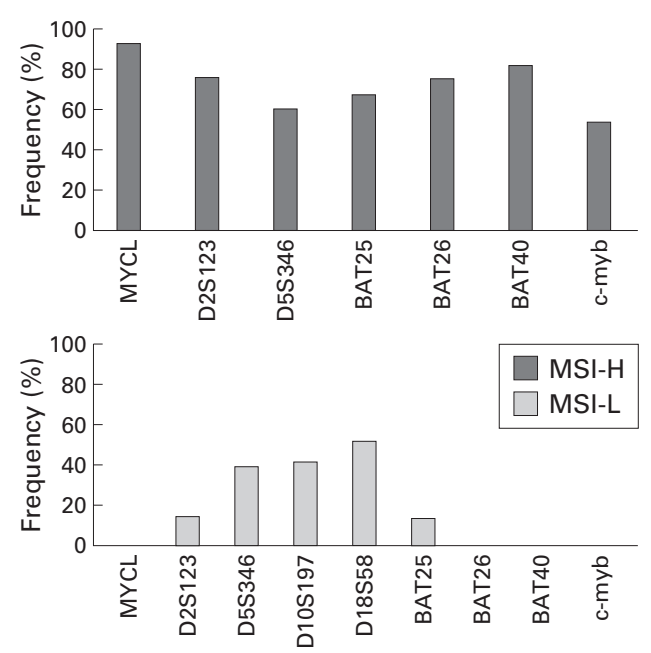

Figure 2 Frequency of bandshifts in microsatellite markers used to distinguish MSI-H and MSI-L adenomas. All markers are sensitive for MSI-H adenomas whereas dinucleotide markers (particularly D5S346, D10S197, and D18S58) are sensitive for MSI-L adenomas. 
Table 2 Frequency of microsatellite instability and target gene mutation

\begin{tabular}{|c|c|c|c|c|c|c|c|c|c|}
\hline & \multirow[b]{2}{*}{$n$} & \multirow[b]{2}{*}{$M S S^{a}$} & \multirow[b]{2}{*}{$M S I-L^{b}$} & \multirow[b]{2}{*}{$M S I-H^{c}$} & \multicolumn{5}{|c|}{ Mutation at coding region } \\
\hline & & & & & $T G F \beta R I I(A) 10^{d}$ & $I G F 2 R(G) 8^{e}$ & $B A X(G) 8^{f}$ & $h M S H 3(A) 8^{g}$ & $h M S H 6(C) 8^{h}$ \\
\hline Hyperplastic polyp & 17 & 15 & 2 & 0 & 0 & 0 & 0 & 0 & 0 \\
\hline Adenoma & 30 & 6 & 8 & 16 & 1 & 2 & 2 & 3 & 4 \\
\hline
\end{tabular}

${ }^{a}$ MSS (microsatellite stable), no microsatellite instability at nine markers; ${ }^{b} \mathrm{MSI}-\mathrm{L}$, microsatellite instability at less than $40 \%$ of markers; ${ }^{\mathrm{C}} \mathrm{MSI}-\mathrm{H}$, microsatellite instability was present at $40 \%$ of markers or more; ${ }^{\mathrm{d} T G F} \beta \mathrm{RII}(\mathrm{A}) 10$, poly(A) 10 tract of TGF $\beta$ receptor type II gene; ${ }^{\mathrm{e}} \mathrm{IGF} 2 \mathrm{R}(\mathrm{G}) 8$, poly(G) 8 tract of IGF receptor type 2 gene; ${ }^{\mathrm{f}} \mathrm{BAX}(\mathrm{G}) 8$, poly $(\mathrm{G}) 8$ tract of BAX gene; ${ }^{\mathrm{h}} \mathrm{hMSH} 3(\mathrm{~A}) 8$, poly(A)8 tract of human MSH3 gene; ${ }^{\mathrm{h} h M S H} 6(\mathrm{C}) 8$, poly(C) 8 tract of human MSH6 gene.

MUTATION ANALYSIS OF REPEAT SEQUENCES OF TGFßR-II, IGF2R, BAX, hMSH3, AND hMSH6 GENES The presence of mutation of the poly(A) 10 tract of TGFßRII, ${ }^{31}$ the poly(G) 8 tract of IGF2R, ${ }^{11}$ the poly $(\mathrm{G}) 8$ tract of $\mathrm{BAX},{ }^{12}$ the poly(A) 8 tract of the hMSH3 gene, ${ }^{32}$ and the poly(C) 8 tract of the hMSH6 gene ${ }^{32}$ was investigated by PCR and subsequent polyacrylamide gel electrophoresis. PCR was undertaken as for MSI testing. After amplification, PCR products were separated by electrophoresis in $5 \%$ or $8 \%$ denaturing polyacrylamide $(19: 1)$ gel according to the size of products, and visualized by autoradiography. The presence of bandshifts or an additional band was interpreted as a mutation (fig 1 ).

IMMUNOHISTOCHEMISTRY

Paraffin sections $(4 \mu \mathrm{m})$ were fixed to Superfrost Plus charged slides (Menzelgläser, Braunschweig, Germany) and dried overnight at $37^{\circ} \mathrm{C}$. The sections were dewaxed and rehydrated to distilled water through descending graded alcohols. Heat antigen retrieval was performed by autoclaving the sections in $0.001 \mathrm{M}$ EDTA ( $\mathrm{pH}$ 8.0) for 15 minutes. After cooling, the sections were transferred to Tris buffered saline (TBS), $\mathrm{pH}$ 7.4. Endogenous peroxidase activity was quenched by incubating in $1 \% \mathrm{H}_{2} \mathrm{O}_{2}$ and $0.1 \% \mathrm{NaN}_{3}$ in TBS for 10 minutes. Following thorough washing in TBS, sections were immersed in $4 \%$ commercial non-fat skim milk powder in TBS for 15 minutes to inhibit non-specific antibody binding, before being transferred to a humidified chamber and covered with $10 \%$ normal (non-immune) goat serum for 30 minutes. Excess serum was decanted from the sections which were then incubated overnight at room

Table 3 Relationship between microsatellite instability status and clinicopathological features of adenomas

\begin{tabular}{|c|c|c|c|c|c|}
\hline & $n$ & $M S S^{a}$ & $M S I-L^{b}$ & $M S I-H^{c}$ & $p$ Value $^{d}$ \\
\hline \multicolumn{6}{|l|}{ Sex } \\
\hline Male & 9 & 3 & 1 & 5 & \\
\hline Female & 21 & 3 & 7 & 11 & 0.7730 \\
\hline \multicolumn{6}{|l|}{ Age $(y)$} \\
\hline$<40$ & 6 & 3 & 0 & 3 & \\
\hline $40-59$ & 9 & 1 & 4 & 4 & \\
\hline $60+$ & 15 & 2 & 4 & 9 & 0.7048 \\
\hline \multicolumn{6}{|l|}{ Location } \\
\hline Proximal colon & 8 & 0 & 1 & 7 & \\
\hline Distal colon & 22 & 6 & 6 & 10 & 0.691 \\
\hline \multicolumn{6}{|l|}{ Size $(\mathrm{mm})$} \\
\hline$<5$ & 14 & 3 & 2 & 9 & \\
\hline $5-9$ & 9 & 2 & 3 & 4 & \\
\hline $10+$ & 7 & 3 & 1 & 3 & 0.5148 \\
\hline \multicolumn{6}{|l|}{ Dysplasia } \\
\hline Low grade & 13 & 4 & 6 & 3 & \\
\hline High grade & 17 & 2 & 2 & 13 & 0.004 \\
\hline
\end{tabular}

${ }^{a}$ MSS (microsatellite stable), no microsatellite instability at nine markers; ${ }^{\mathrm{b}} \mathrm{MSI}-\mathrm{L}$, microsatellite instability at less than $40 \%$ of markers; ${ }^{\circ} \mathrm{MSI}-\mathrm{H}$, microsatellite instability at $40 \%$ or more markers. ${ }^{d}$ Fisher's exact test for MSS and MSI-L $v$ MSI-H for each clinical feature. temperature with primary monoclonal antibodies to hMLH1 and hMSH2. The monoclonal antibodies G168-15 (anti-hMLH1 diluted $1: 75$ in TBS) and Ab-2 (anti-hMSH2 diluted 1:120) were obtained from PharMingen (San Diego, California, USA) and Oncogene Research Products (Cambridge, Massachusetts, USA), respectively.

Following the incubations, sections were washed thoroughly in three changes of TBS for five minutes each. Sections were then incubated for 45 minutes with appropriate biotinylated secondary antibodies (Zymed Laboratories, San Francisco, California, USA), and then streptavidin-horseradish peroxidase conjugate (Zymed) for 15 minutes. Antigenic sites were revealed by incubating sections in $0.05 \%$ 3,3'-diaminobenzidine in Tris saline with $\mathrm{H}_{2} \mathrm{O}_{2}$ as substrate. After washing in gently running tap water, the sections were lightly counterstained with haematoxylin, dehydrated through graded alcohols, cleared in xylene, and mounted with DePeX.

STATISTICAL ANALYSIS

Associations between clinicopathological variables and the frequency of genetic changes were assessed by $\chi^{2}$, Fisher's exact test, or the Wilcoxon rank sum statistic using a Statxact package. Probability ( $p$ ) values of $<0.05$ were considered significant.

\section{Results}

PATHOLOGICAL FEATURES OF POLYPS FROM

HNPCC SUBJECTS

The sites and pathological features of the 47 colorectal polyps are summarised in table 1 . Seven of 14 adenomas (50\%) measuring less than $5 \mathrm{~mm}$, six of nine adenomas (66.7\%) measuring 5-9 $\mathrm{mm}$, and four of seven adenomas $(57.1 \%)$ of $\geqslant 10 \mathrm{~mm}$ revealed high grade dysplasia. There was no correlation between adenoma size and grade of dysplasia (Wilcoxon rank sum statistic, $\mathrm{p}=0.619$ ).

\section{FREQUENCY OF MICROSATELLITE INSTABILITY} Informative PCR products were obtained from $60 \%$ of the nine microsatellite markers and bandshifts at four loci are shown for an MSI-H adenoma (fig 1). Bandshifts occurred with similar frequencies in MSI-H adenomas regardless of marker type whereas dinucleotide markers were more sensitive for MSI-L adenomas (fig 2). Two of 17 (11.8\%) hyperplastic polyps showed MSI at one marker (D5S346). No hyperplastic polyp was classified as MSI-H. Twenty four (80\%) of 30 adenomas revealed MSI. Eight of 24 (33.3\%) adenomas were classified as MSI-L and 16 of 
Table 4 Relationship between microsatellite instability status and mutations in coding region of hereditary non-polyposis colorectal cancer adenomas

\begin{tabular}{lrlllll}
\hline$\% M S I^{a}$ & $n$ & $T G F \beta R I I(A) 10^{b}$ & $I G F 2 R(G) 8^{c}$ & $B A X(G) 8^{d}$ & $h M S H 3(A) 8^{c}$ & $h M S H 6(C) 8^{f}$ \\
\hline$<40$ & 14 & 0 & 0 & 0 & 0 & 0 \\
$40-59$ & 6 & 0 & 1 & 1 & 1 & 0 \\
$60-79$ & 3 & 0 & 0 & 1 & 1 & 0 \\
$80+$ & 7 & 1 & 1 & 0 & 1 & $4^{\mathrm{g}}$
\end{tabular}

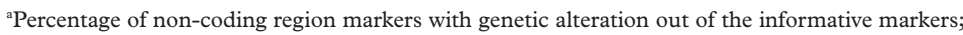
${ }^{\text {bTGF}} \beta \mathrm{RII}(\mathrm{A}) 10$, poly(A) 10 tract of TGF $\beta$ receptor type II gene; 'IGF2R(G) 8 , poly(G) 8 tract of IGF receptor type 2 gene; ${ }^{\mathrm{d}} \mathrm{BAX}(\mathrm{G}) 8$, poly $(\mathrm{G}) 8$ tract of $\mathrm{BAX}$ gene; ${ }^{\mathrm{e}} \mathrm{hMSH} 3(\mathrm{~A}) 8$, poly(A) 8 tract of human MSH3 gene; fhMSH6(C)8, poly(C)8 of human MSH6 gene.

${ }^{g}$ Fisher's exact test for $\%$ MSI of $40-79$ and $+80 v$ the presence of mutation of hMSH6(C) 8 was significant $(\mathrm{p}<0.02)$.

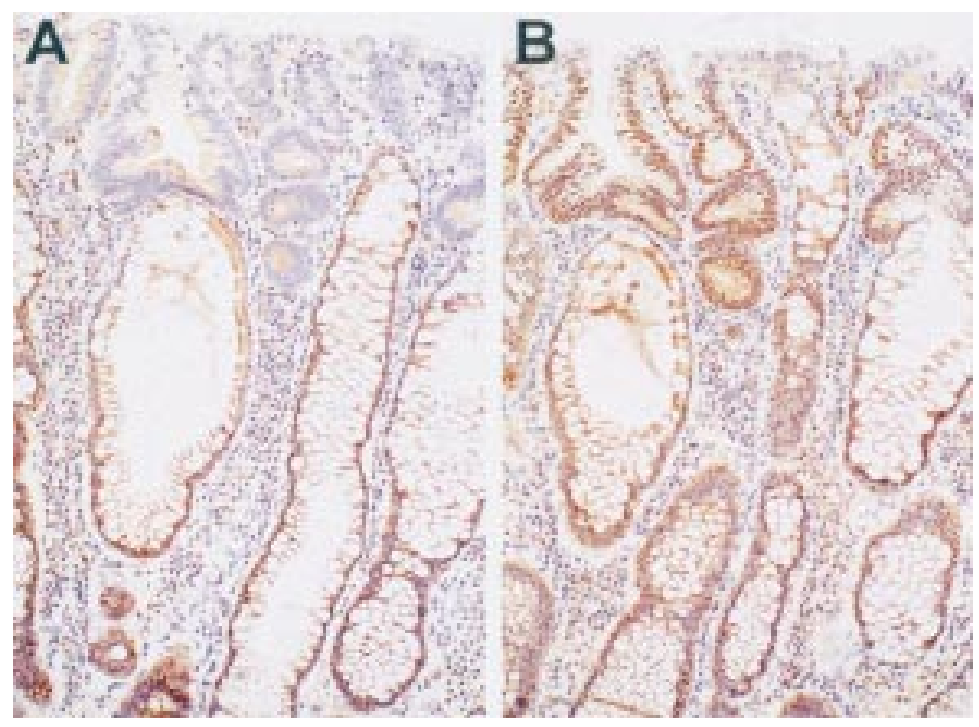

Figure 3 Loss of hMSH2 (A) and retention of hMLH1 (B) in a $3 \mathrm{~mm}$ tubular adenoma that was MSI-H. The subject had a known germline mutation of hMSH2.

Immunohistochemical staining with anti-hMSH2 and anti-MLH1.

$24(66.7 \%)$ as MSI-H. Only one MSI-L adenoma showed bandshifts at more than one locus (three dinucleotide loci). Bandshifts were seen at 10/63 (16\%) evaluable loci in MSI-L adenomas. In contrast, 67/93 (72\%) evaluable loci in MSI-H adenomas showed bandshifts. Twelve mutations in coding regions were identified in nine adenomas from six HNPCC subjects. No coding region mutations were identified in hyperplastic polyps (table 2).

MSI STATUS AND CLINICOPATHOLOGICAL FEATURES OF HNPCC POLYPS

Adenomas displaying high grade dysplasia revealed MSI-H more frequently than those with low grade dysplasia (Fisher's exact test, $\mathrm{p}=0.004)$. There was no significant association between MSI status and sex, age, location, or size of adenomas. Nine of $14(64.3 \%)$ adenomas less than $5 \mathrm{~mm}$ in size, four of nine $(44.4 \%)$ of $5-9 \mathrm{~mm}$, and three of seven $(42.9 \%)$ more than $9 \mathrm{~mm}$ showed MSI-H (table 3). The two hyperplastic polyps classified as MSI-L were obtained from the proximal colon. One was $5 \mathrm{~mm}$ and another $10 \mathrm{~mm}$ in size.

MUTATION OF REPEAT SEQUENCES IN CODING REGIONS OF TGFßRII, IGF2R, BAX, hMSH3, AND hMSH6

Mutations in repeat sequences of coding regions were detected in nine of 30 adenomas. One mutation was identified at TGF $\beta$ RII, two mutations at IGF2R and BAX, three mutations at hMSH3, and four mutations at hMSH6. Two adenomas showed mutations at two genes, one at IGF2R and hMSH6 and the second at hMSH3 and hMSH6. All nine adenomas with mutations in coding regions were MSI-H and eight $(88.9 \%)$ showed high grade dysplasia. Three were only 2 or $3 \mathrm{~mm}$ in size and six of nine $(66.7 \%)$ were less than $1 \mathrm{~cm}$.

MSI-H status of adenomas was classified into three grades depending on the proportion of MSI positive markers among markers providing informative PCR products. Six adenomas showed MSI at $40-59 \%$ of markers, three at $60-79 \%$, and seven at $80 \%$ or more. Four of four cases which showed mutations at hMSH6 revealed MSI at more than $80 \%$ of microsatellite markers (table 4 ). There was a significant association between MSI involving $80 \%$ of loci or more and mutation of hMSH6 $(\mathrm{p}=0.02)$.

\section{IMMUNOHISTOCHEMISTRY}

Twenty four adenomas gave evaluable results with immunohistochemistry (fig 3). Distribution according to microsatellite status and expression of hMLH1 and hMSH 2 are shown in table 5. One of six MSS adenomas showed loss of hMLH1 protein while six of seven MSI-L adenomas showed loss of hMLH1 (one) or hMSH2 (five) protein. The results in 83 sporadic and 46 familial colorectal cancers are also shown in table 5 . There were 15 MSI-L and MSI-H adenomas from subjects with a known germline mutation. All 15 showed loss of a mismatch repair protein that was concordant with germline status.

Table 5 DNA mismatch repair (MMR) protein expression in hereditary non-polyposis colorectal cancer adenomas, familial colorectal cancers (CRC), and sporadic colorectal cancers

\begin{tabular}{|c|c|c|c|c|c|c|}
\hline & \multicolumn{2}{|c|}{ HNPCC adenomas } & \multicolumn{2}{|c|}{ Familial CRC† } & \multicolumn{2}{|c|}{ Sporadic $C R C$} \\
\hline & $\begin{array}{l}\text { MSS/MSI-L } \\
(n=13)\end{array}$ & $\begin{array}{c}M S I-H \\
(n=11)\end{array}$ & $\begin{array}{l}M S S \\
(n=21) t t\end{array}$ & $\begin{array}{l}\text { MSI-H } \\
(n=25) t+t\end{array}$ & $\begin{array}{l}\text { MSS } / M S I-L \\
(n=60)\end{array}$ & $\begin{array}{l}M S I-H \\
(n=23)\end{array}$ \\
\hline No loss & 6 & 0 & 20 & 2 & 60 & $1^{\star}$ \\
\hline hMLH1 loss & 2 & 2 & 0 & 13 & 0 & 21 \\
\hline hMSH2 loss & 5 & 9 & 1 & 10 & 0 & $1 \star \star \star$ \\
\hline
\end{tabular}

Loss of MMR protein in MSS/MSI-L lesions: (a) HNPCC adenoma $v$ familial CRC ( $p=0.001$, Fisher's exact test); (b) HNPCC adenoma $v$ sporadic CRC $(\mathrm{p}<0.001$, Fisher's exact test).

tAt least two first degree relatives with CRC; +tmajority will not be HNPCC; †tmajority will be HNPCC.

${ }^{\star}$ Borderline MSI-L/MSI-H; ${ }^{\star \star}$ aged 34 and adopted (likely HNPCC). 


\section{Discussion}

In this study, $80 \%$ of colorectal adenomas from subjects with HNPCC displayed DNA microsatellite instability (MSI). Others have shown that $57-93 \%^{71620} 33$ of HNPCC adenomas reveal MSI. Using 26 dinucleotide microsatellite markers, Jacoby and colleague ${ }^{20}$ found that a lower proportion of mutated microsatellite loci were detected in completely benign adenomas than in the benign areas of adenomas with foci of malignancy. The stage of MSI-L appears to be a distinct and perhaps early phase, associated primarily with dinucleotide instability (fig 2). Whether MSI-H adenomas must pass through an MSI-L stage or whether the MSI-H phenotype can arise de novo is unknown. It is of interest that one of six MSS adenomas showed loss of hMLH1 protein and six of seven MSI-L adenomas showed loss of hMLH1 (one) or hMSH2 (five) protein (table 5). The MSS adenoma with loss of hMLH1 was from a subject with a germline mutation of hMLH1. No bandshifts were seen at six of nine loci with evaluable PCR products, including BAT25 and BAT40. These findings are in contrast with sporadic and familial MSS/MSI-L colorectal cancers (table 5). This would suggest that MSI-L may occur as a stage in the evolution of MSI-H status in HNPCC whereas MSI-L and MSI-H appear to be diverging phenotypes in sporadic colorectal cancer. ${ }^{8}$ The rarity of MSI-L (and MSS) colorectal cancer in HNPCC (we found two MSI-L and 68 MSI-H cancers in subjects with HNPCCunpublished observations) suggests that the transition from MSI-L to MSI-H is occurring at the stage of adenoma in HNPCC. Cawkwell et al found a similar association between MSI-H status and loss of DNA mismatch repair gene expression in colorectal cancer. ${ }^{34}$ It is likely that MSI-H adenomas are more prone to progress to cancer. This would be consistent with our finding of a significant association between MSI-H status and high grade dysplasia $(p=0.004)$.

It is noteworthy that 11 of $14(78.6 \%)$ adenomas less than $5 \mathrm{~mm}$ in size showed MSI and nine of these $(81.9 \%)$ were MSI-H. The smallest adenoma with MSI-H in this study was $2 \mathrm{~mm}$ in size and more than $50 \%$ of adenomas less than $5 \mathrm{~mm}$ in size revealed high grade dysplasia. MSI has been described in foci of colorectal neoplasia of microscopic size (aberrant crypt foci) $\cdot{ }^{17}$ Multiple aberrant crypt foci developed in the colonic mucosa of MSH2 deficient mice. ${ }^{35}$ It is evident that the mutator phenotype (MSI-H as well as MSI-L) is established at an early stage of adenoma formation in HNPCC subjects. This may explain the high frequency of interval cancer.

TGF $\beta R I^{36}$ and IGF2R ${ }^{11}$ participate in the control of epithelial cell growth whereas BAX regulates apoptosis. ${ }^{37}$ These genes have repetitive tracts in their coding sequences and are frequently mutated in the colorectal cancers of HNPCC or sporadic MSI-H cancers. ${ }^{10-12}$ hMSH3 and hMSH6 participate in the DNA repair system by forming complexes with the MSH2 protein. ${ }^{38}$ hMSH3 and hMSH6 have repeat sequences in their coding regions and frameshift mutations have been detected in HNPCC cancers and sporadic cancers showing $\mathrm{MSI}^{21}$ Germline mutations of hMSH6 have also been reported. ${ }^{39}$ Mutation of TGF $\beta$ RII or BAX was found in $63-90 \%^{716}{ }^{29}$ of sporadic MSI-H cancers and in $54 \%{ }^{19}$ of HNPCC cancers. In adenomas, the frequency of mutation of these genes was $50-64 \%^{716}$ and $15 \%,{ }^{19}$ respectively. These findings relate mutation of TGF $\beta$ RII with early adenoma progression and BAX with the transition from adenoma to carcinoma. ${ }^{10} 20$

In the present study, nine of 16 (56\%) MSI-H adenomas were found to have mutations at one or more coding regions while none of 14 MSI-L or MSS cases showed coding region mutations. This fits with the low frequency of mononucleotide instability in MSI-L lesions (fig 2) as target coding sequences comprise mononucleotide runs. There was one $(6.3 \%)$ mutation of TGF $\beta$ RII and two mutations of IGF2R (12.3\%) and BAX $(12.6 \%)$. Three $(18.8 \%)$ and four $(25.0 \%)$ of 16 MSI-H adenomas had mutations at hMSH3 and hMSH6, respectively. No adenoma had mutations at more than two coding regions. Compared with earlier studies ${ }^{16}$ the frequency of mutation in coding regions, particularly in TGF $\beta$ RII, was low. These data suggest that mutations of TGF $\beta$ RII, IGF2R, and BAX follow no sequential pattern but cluster within adenomas showing MSI-H and high grade dysplasia (table 4). Other genes, including CDX-2, ${ }^{13} \mathrm{E} 2 \mathrm{~F}-4,{ }^{14}$ caspase-5, ${ }^{15}$ and as yet unknown genes may also be involved in adenoma progression.

Although HNPCC patients develop adenomas at about the same rate as the general population, HNPCC adenomas are more prone to malignant conversion than their sporadic counterparts. ${ }^{4}$ Somatic mutations of additional mismatch repair genes may serve as secondary mutators and accelerate the accumulation of MSI and further coding region mutations. ${ }^{21}$ Our data suggest that hMSH6 and hMSH3 may function as secondary mutators. The hMSH6 mutation occurred only in adenomas with the highest levels of MSI (table 4). However, the possibility that mutation of MSH6 could be an epiphenomenon, secondary to the establishment of high levels of MSI-H, cannot be excluded. Furthermore, our data suggest that mutation of $\mathrm{hMSH} 3$ and hMSH6 cannot be the only explanation for the critical transition from MSI-L to MSI-H.

In spite of the right sided predominance of colon cancer in HNPCC and MSI positive sporadic colon cancers, ${ }^{40}$ our data showed no significant association between location of adenoma and MSI (table 3 ). Of nine adenomas with mutation of coding genes, only two were derived from the proximal colon. Jacoby and colleagues $^{20}$ and Akiyama and colleagues ${ }^{16}$ also indicated no site predilection for HNPCC adenomas. The two hyperplastic polyps with MSI were obtained from the proximal colon. One hyperplastic polyp with MSI and TGF $\beta$ RII mutation has been reported. ${ }^{7}$ The current data provide little evidence that sporadic hyperplastic polyps play a role in the 
evolution of colorectal cancer in HNPCC but do not exclude a minor role in the case of proximally located polyps. ${ }^{41}$ The six MSS adenomas could be coincidental sporadic adenomas, a suggestion that would be supported by an age relationship and retention of expression of hMLH1 and hMSH2 in five of the six adenomas. In fact, three MSS adenomas occurred in subjects aged less than 40 (table 3 ). It appears that even colorectal cancers may occasionally be MSS in individuals carrying a mismatch repair gene germline mutation. ${ }^{14}$

In conclusion, most colorectal adenomas in HNPCC show low or high levels of DNA microsatellite instability and most of these show loss of hMLH1 or hMSH2. The transition to high grade dysplasia is associated with the MSI-H phenotype and is accompanied by mutation of coding sequences in TGF $\beta$ RII, IGF2R, and BAX. MSH3 and MSH6 may add to the MSI burden as secondary mutators.

We thank Brenda Mason for secretarial support and Clay Winterford for photographic assistance. Supported by NIH/
USA grant No 1 U01 CA74778-01 (Collaborative Family Registry for Colorectal Cancer Studies).

1 Jass JR. Colorectal adenomas in surgical specimens from subjects with hereditary non-polyposis colorectal cancer. subjects with hereditary non-pol
Histopathology 1995;27:263-7.

2 Shibata D, Navidi W, Salovaara R, et al. Somatic microsatellite mutations as molecular tumor clocks. Nat Med 1996;2: 676-81.

3 Vasen HFA, Nagengast FM, Meera Khan P. Interval cancers in hereditary non-polyposis colorectal cancer (Lynch syndrome). Lancet 1995;345:1183-4.

4 Jass JR, Stewart SM, Stewart J, et al. Hereditary nonpolyposis colorectal cancer: morphologies, genes and mutations. Mutat Res 1994;290:125-33.

5 Ahlquist DA. Aggressive polyps in hereditary nonpolyposis colorectal cancer: targets for screening. Gastroenterology 1995;108:1590-2.

6 Aaltonen LA, Peltomaki PS, Leach FS, et al. Clues to the pathogenesis of familial colorectal cancer. Science 1993; 260:812-16.

7 Konishi M, Kikuchi-Yanoshita R, Tanaka K, et al. Molecular nature of colon tumor in hereditary nonpolyposis colorectal cancer, familial polyposis, and sporadic colon cancer. ectal cancer, familial polyposis, and
Gastroenterology 1996;111:307-17.

8 Jass JR, Biden KG, Cummings MC, et al. Characterization of a subtype of colorectal cancer combing features of the suppressor and mild mutator pathways. F Clin Pathol 1999 52:455-60.

9 Simms LA, Radford-Smith G, Biden KG, et al. Reciprocal relationship between the tumor suppressors p53 and BAX in primary colorectal cancers. Oncogene 1998;17:2003-8.

10 Markowitz S, Wang J, Myeroff L, et al. Inactivation of the type II TGF- beta receptor in colon cancer cells with microsatellite instability. Science 1995;268:1336-8.

11 Souza RF, Appel R, Yin J, et al. Microsatellite instability in the insulin-like growth factor II receptor gene in gastrointestinal tumors. Nat Genet 1996;14:255-7.

12 Rampino N, Yamamoto H, Ionov Y, et al. Somatic frameshift mutations in the BAX gene in colon cancers of the microsatellite mutator phenotype. Science 1997;275: the micro

13 Wicking C, Simms LA, Evans T, et al. CDX2, a human homologue of Drosophila caudal, is mutated in both alleles in a replication error positive colorectal cancer. Oncogene 1998;17:657-9.

14 Fujiwara T, Stolker JM, Watanabe T, et al. Accumulated clonal genetic alterations in familial and sporadic colorecta carcinomas with widespread instability in microsatellite sequences. Am F Pathol 1998;153:1063-78.

15 Schwartz S, Yamamoto H, Navarro M, et al. Frameshift mutations at mononucleotide repeats in caspase- 5 and other target genes in endometrial and gastrointestinal cancer of the microsatellite mutator phenotype. Cancer Res 1999;59:2995-3002.
16 Akiyama Y, Iwanaga R, Saitoh K, et al. Transforming growth factor B type II receptor gene mutations in adenomas hereditary nonpolyposis colorectal cancer. Gastroenterology 1997;112:33-9

17 Heinen CD, Shivapurkar N, Tang Z, et al. Microsatellite instability in aberrant crypt foci from human colons. Cancer Res 1996;56:5339-41.

18 Grady WM, Rajput A, Myeroff L, et al. Mutation of the type II transforming growth factor-beta receptor is coincident with the transformation of human colon adenomas to malignant carcinomas. Cancer Res 1998;58:3101-4.

19 Yagi OK, Akiyama Y, Nomizu T, et al. Proapoptotic gene $\mathrm{BAX}$ is frequently mutated in hereditary nonpolyposis colorectal cancers but not in adenomas. Gastroenterology 1998;114:268-74.

20 Jacoby RF, Marshall DJ, Kailas S, et al. Genetic instability associated with adenoma to carcinoma progression in hereditary nonpolyposis colon cancer. Gastroenterology 1995;109:73-82.

21 Yamamoto H, Sawai H, Perucho M. Frameshift somatic mutations in gastrointestinal cancer of the microsatellite instability mutator phenotype. Cancer Res 1997;57:4420-6.

22 Vasen HF, Mecklin JP, Khan PM, et al. The International Collaborative Group on Hereditary Non-Polyposis Colorectal Cancer (ICG-HNPCC). Dis Colon Rectum 1991;34: $424-5$.

23 Iino H, Jass JR, Simms LA, et al. DNA microsatellite instability in hyperplastic polyps, serrated adenomas, and mixed polyps: a mild mutator pathway for colorectal cancer? $\mathcal{f}$ polyps: a mild mutator

24 Mäkelä TP, Hellsten E, Vesa J, et al. An Alu variable polyA repeat polymorphism upstream of L-myc at $1 \mathrm{p} 32$. Hum Mol Genet 1992;1:217.

25 Leach FS, Nicolaides NC, Sistonen P, et al. Three dinucleotide repeat polymorphisms proximal to the D2S123 locus. Hum Mol Genet 1994;3:2082.

26 Spirio L, Joslyn G, Nelson L, et al. A CA repeat 30-70 KB downstream from the adenomatous polyposis coli (APC) gene. Nucleic Acids Res 1991;19:6348.

27 Weissenbach J, Gyapay G, Dib C, et al. A second generation linkage map of the human genome. Nature 1992;359:794801 .

28 Dib C, Faure S, Fizames C, et al. A comprehensive map of the human genome based on 5,264 microsatellites. Nature 1996;380:152-4.

29 Parsons R, Myeroff LL, Liu B, et al. Microsatellite instability and mutations of the transforming growth factor $\beta$ type II receptor gene in colorectal cancer. Cancer Res 1995;55: II receptor

30 Biden KG, Simms LA, Cummings M, et al. Expression of $\mathrm{Bcl}-2$ protein is decreased in colorectal adenocarcinomas with microsatellite instability. Oncogene 1999;18:1245-9.

31 Myeroff LL, Parsons R, Kim S-J, et al. A transforming growth factor $\beta$ receptor type II gene mutation common in colon and gastric but rare in endometrial cancers with microsatellite instability. Cancer Res 1995;55:5545-7.

32 Malkhosyan S, Rampino N, Yamamoto H, et al. Frameshift mutator mutations. Nature 1996;382:499-500.

33 Aaltonen LA, Peltomäki P, Mecklin JP, et al. Replication errors in benign and malignant tumors from hereditary nonpolyposis colorectal cancer patients. Cancer Res 1994; 54:1645-8

34 Cawkwell L, Gray S, Murgatroyd H, et al. Choice of management strategy for colorectal cancer based on diagnostic immunohistochemical test for defective mismatch repair. Gut 1999;45:409-15.

35 Reitmair AH, Cai J-C, Bjerknes M, et al. MSH2 deficiency contributes to accelerate APC-mediated intestinal tumoricontributes to accelerate APC-mediate
genesis. Cancer Res 1996;56:2922-6.

36 Wrana JL, Attisano L, Wieser R, et al. Mechanism of activation of the TGF- $\beta$ receptor. Nature 1994;370:341-7.

37 Oltvai ZN, Milliman CL, Korsmeyer SJ. Bcl-2 heterodimerizes in vivo with a conserved homolog, BAX, that accelerates programed cell death. Cell 1993;74:609-19.

38 Johnson RE, Kovvali GK, Prakash L, et al. Requirement of the Yeast MSH3 and MSH6 genes for MSH2-dependent genomic stability. F Biol Chem 1996;271:7285-8.

39 Akiyama Y, Sato H, Yamada T, et al. Germ-line mutation of the hMSH6/GTBP gene in an atypical hereditary nonpolyposis colorectal cancer kindred. Cancer Res 1997;57:39203 .

40 Thibodeau SN, Bren G, Schaid D. Microsatellite instability in cancer of the proximal colon. Science 1993;260:816-19.

41 Jass JR, Cottier DS, Pokos V, et al. Mixed epithelial polyps in association with hereditary non-polyposis colorectal cancer providing an alternative pathway of cancer histogenesis. Pathology 1997;29:28-33. 